\title{
ABSTRAK \\ PENGARUH PENDIDIKAN KESEHATAN TENTANG \\ DHF TERHADAP PENGETAHUAN PENCEGAHAN DHF PADA SANTRI PONDOK PUTRI WILAYAH MILAQ AL-QODIRI JEMBER.
}

\author{
(1)Eka Suryaningtyas S.kep.M.kep
}

\begin{abstract}
Pendidikan kesehatan adalah suatu proses perubahan pada diri manusia yang ada hubungannya dengan tercapainya tujuan kesehatan perorangan dan masyarakat. Pendidikan kesehatan bukanlah sesuatu yang dapat diberikan oleh seseorang kepada orang lain dan bukan pula sesuatu rangkaian tata laksana yang akan dilaksana ataupun hasil yang akan dicapai, melainkan suatu proses perkembangan yang selalu beubah secara dinamis dimana seseorang dapat menerima atau menolak keterangan baru yang ada hubungannya dengan tujuan hidup sehat (Nyswander,1947 dalam Azwar 1983).

Metode penelitian ini menggunakan desain Pre Experimen dengan One Group Pra-testPost-Test Design. Pengambilan sampel menggunakan teknik Total Sampling, dengan jumlah sampel sebanyak 58 siswa yang memenuhi kriteria. Instrumen penelitian ini mengguanakan kuisioner. Hasil penelitian dengan uji Wilcoxon $(\alpha=0,05)$ menunjukkan bahwa ada pengaruh pendidikan kesehatan tentang dhf terhadap pengetahuan pencegahan dhf.

Hasil analisa univariat sebelum dilakukan pendidikan kesehatan yang memiliki pengetahuan baik sebanyak 4 (6,9\%) dan setelah dilakukan pendidikan kesehatan diketahui siswa yang memiiki pengetahuan baik untuk pencegahan dhf sebanyak 39 (67,2\%). Dengan uji Wilcoxon di dapat $\mathrm{P}$ value 0,000

Kesimpulan penelitian ini bahwa ada pengaruh pendidikan kesehatan tentang dhf terhadap pengetahuan pencegahan dhf.
\end{abstract}

Kata kunci : Pendidikan Kesehatan; Tentang Dhf; Pengetahuan;Pencegahan Dhf; Santri

Pondok Putri 


\section{ABSTRACT \\ THE EFFECT OF HEALTH EDUCATION ON THEKNOWLEDGE OF DHF DHF PREVENTIONIN STUDENT LODGE DAUGHTER REGION MILAQ AL-QODIRI JEMBER.}

Health education is a process of change in a human being that has to do with the achievement of the health of individuals and communities. Health education is not something that can be given by one person to another, nor a series of procedures that will be implemented and results to be achieved, but rather a process of changing the dynamic where one can acceptor reject the new information that has to do with purpose health life. (Nyswander, 1947 dalam Azwar 1983 ).

This research method using pre design experiment with One Group Pra- Test-post-test design. Sampling using techniques Total Sampling. With a total sample of 58 student who meet the criteria. The instrument Of this study using questionnaries. The result of research to test Wilcoxon $(\alpha=0,05)$ show that there is influence of health education on the knowledge of DHF prevention.

Results of univariate analysis before health education who has good knowledge as much as $4(6,9 \%)$ and after health education is known to student who have a good knowledge of DHF prevention as much as $39(67,2 \%)$. With tesyt Wilcoxon in the can P Value 0,000.

The conclusion of this study that there is influence of health education on the knowledge of DHF prevention.

Keywords : Health Education ; About DHF ; Knowledge ; DHF prevention Students cottage daughter 
LATAR BELAKANG

Rumah yang sehat dapat menceegah penularan penyakit dengan sanitasi dasar seperti pembuangan air limbah, pembuangan sampah harus memenuhi kesehatan syarat kesehatan sehingga rumah tidak lagi menjadi sarang dan sumber penyakit seperti demam berdarah dengue (DHF).

Dewasa ini penyuluhan kesehatan tentang berbagai penyakit telah digalakkan oleh oleh pemerintah agar kesadaran masyarakat meningkat. Begitu pula dengan penyuluhan tentang DHF di berbagai wilayah bertujuan untuk menjadikan pola pikir sikap dan kesadaran masyarakat untuk bertindak semakin meningkat.

Pendidikan kesehatan merupakan suatu proses yang menjembatani kesenjangan antara informasi dan tingkah laku kesehatan. Pendidikan kesehatan memotivasi seseorang untuk menerima informasi kesehatan dan berbuat sesuai dengan informasi tersebut agar mereka menjadi lebih tahu dan lebih sehat. (Budioro, 1998).

Berdasarkan data Profil Kesehatan Indonesia tahun 2010 jumlah kasus DHF pada tahun 2010 sebanyak 156.086 kasus dengan jumlah kematian akibat DHF sebesar
1.358 orang. Inciden Rate (IR) penyakit DHF pada tahun 2010 adalah 65,7 per 100.000 penduduk dan Case Fatality Rate (CFR) sebanyak 0,87\%. Pada tahun 2009 IR penyakit DHF sebesar 68,22 per 100.000 penduduk. Sedangkan di tahun 2008 angka kejadiannya DHF sebesar 59,02\% per 100.000 penduduk dengan Case Fatality Rate (CFR) 0,86\% (Kemenkes RI, 2011).

DHF sudah dikenal di Indonesia sejak tahun 1968, penyakit ini pertama kali dilaporkan terjadi di Surabaya, Jawa Timur. Sejak saat itu, DHF menyebar hingga ke seluruh Indonesia. Selama tahun 1996-2005 tercatat 334.685 kasus DHF dengan jumlah penderita yang meninggal 3.092 orang.

Provinsi Jawa Timur merupakan salah satu daerah endemik DHF. Berdasarkan mapping insiden DHF Provinsi tahun 2012, Jawa Timur temasuk ke dalam provinsi berwarna merah yang berarti Provinsi dengan insiden KLB (Kejadian Luar Biasa). Menurut Dinas Komunikasi dan informatika Jawa Timur pada tahun 2012. Terdapat 7 kota di Jawa Timur yang termasuk dalam kota KLB DHF. Daerah itu antara lain Kab.Kediri, Kab.Sumenep, Kab.Jember, Kab.Lamongan, Kab.Mojokerto, Kota Madiun, dan Kabupaten Pamekasan. Kondisi ini semakin 
memperparah reputasi Jawa Timur di bidang kesehatan.

Kabupaten Jember salah satu dari 7 kota KLB DHF. Sejak tahun 2008 - 2012 jumlah kasus DHF di Jember terus mengalami peningkatan kecuali pada tahun 2011. Berdasarkan data Dinas Kesehatan, kondisi di Jember pada tahun 2008 terdapat 780 kasus dan meningkat pada tahun 2009 sebesar 983 kasus. Pada tahun 2010 terjadi KLB dengan jumlah 1.494 kasus. Incident pada tahun 2010 mencapai 62 per 100.00 penduduk. Tahun 2011 kondisi DHF cukup bagus karena terjadi penurunan yang cukup signifikan dan hanya terjadi 77 kasus dengan CFR 1,30\%. Namun, pada tahun 2012 kembali meningkat dengan jumlah 260 kasus dan CFR 1,92\%.

Hasil studi pendahuluan yang dilakukan dengan wawancara kepada pengurus bagian koordinator kesehatan pondok pesantren putri al qodiri jumlah santri di wilayah Milaq sejumlah 58 santri. Dari 58 santri tersebut terdapat 34 santri putri yang tidak mengetahui tentang DHF, 3 santri pernah terjangkit penyakit DHF, sedangkan sisanya 24 santri yang mengerti DHF.

Pencegahan DHF harus dicegah melalui 3M yaitu menguras, menutup,
mengubur.Karena jika tidak dicegah dapat terjadi DHF dan yang akan menimbulkan komplikasi pada yang lainnya. Untuk perlu dilakukan identifikasi dan menganalisis pencegahan DHF yang benar dan mengobservasi pencegahan DHF.

Berdasarkan uraian di atas peneliti tertarik untuk melakukan penelitian tentang "Pengaruh Pendidikan Kesehatan Tentang DHF Terhadap Pengetahuan Pencegahan DHF pada Santri Pondok Putri Wilayah Milaq Al-Qodiri Jember

\section{Metode Penelitian}

Pada penelitian ini merupakan penelitian analisis korelasi. Pada penelitian ini tehnik sampling menggunakan "Total sampling". Data dikumpulkan dengan cara menyebar lembar kuesioner dan kepada 58 responden. Kemudian data dianalisis dengan menggunakan uji "Wilcoxon". 


\section{Hasil Penelitian}

Berdasarkan penelitian yang telah dilakukan didapatkan data sebagai berikut:

\section{Data Umum}

\subsubsection{Distribusi responden} berdasarkan umur

Tabel 5.1.1 Distribusi Frekuensi Responden Berdasarkan Umur

Di Pondok Putri AL-QODIRI Jember Bulan Juni 2016

\begin{tabular}{|l|l|l|}
\hline Umur & Jumlah & Persentase(\%) \\
\hline $13-15$ & 30 & $51,7 \%$ \\
\hline $16-18$ & 22 & $37,9 \%$ \\
\hline $19-20$ & 6 & $10,3 \%$ \\
\hline Total & 58 & $100 \%$ \\
\hline
\end{tabular}

Berdasarkan tabel di atas dapat diketahui bahwa setengah frekuensi siswa berusia 16 tahun sebanyak 22 (37,9\%), usia15 tahun sebanyak $30(51,7 \%)$ dan yang paling dikit siswa berusia 19 tahun sebanyak $6(10,3 \%)$

\section{Data Khusus}

5.2.1 Distribusi frekuensi Pengetahuan Pencegahan $\mathrm{DHF}$ sebelum diberikan pendidikan kesehatan. Tabel 5.2.1 Distribusi frekuensi Pengetahuan Pencegahan DHF Sebelum Diberikan Pendidikan Kesehatan di Pondok Putri AL-QODIRI Jember/Bulan Mei 2016

\begin{tabular}{|l|l|l|l|l|l|l|}
\hline \multirow{2}{*}{$\begin{array}{l}\text { Pendidikan } \\
\text { kesehatan }\end{array}$} & \multicolumn{3}{|l|}{ PENGETAHUAN PENCEGAHAN DHF } \\
\cline { 2 - 8 } & Baik & \multicolumn{2}{|l|}{ Cukup } & \multicolumn{2}{l|}{ Kurang } \\
\cline { 2 - 8 } & F & $\%$ & F & $\%$ & F & $\%$ \\
\hline Pre & 4 & 6,9 & 20 & 34,5 & 34 & 58,6 \\
\hline Total & 4 & 6,9 & 20 & 34,5 & 34 & 58,6 \\
& & & & & & \\
\hline
\end{tabular}

Berdasarkan tabel di atas dapat diketahui bahwaPengetahuan Pencegahan DHF di PONDOK PUTRI Al-Qodiri Jember sebelum diberikan pendidikan kesehatan cukup kurang, hal itu dapat dibuktikan bahwa dari 58 santri putri terdapat $4(6,9 \%)$ santri putri masih memiliki Pengetahuan Pencegahan $D H F$ yang baik sedangkan 20 $(34,5 \%)$ santri putri memiliki Pengetahuan Pencegahan DHF yang cukup dan 34 $(58,6 \%)$ santri putri memiliki Pengetahuan Pencegahan $D H F$ yang kurang. 
5.2.2 Distribusi frekuensi Pengetahuan

Pencegahan DHF sesudah diberikan

pendidikan kesehatan

Tabel 5.2.2 Distribusi Frekuensi Sesudah Diberikan Pendidikan Kesehatan di Pondok Putri AL-QODIRI Jember Bulan Mei 2016

\section{Pembahasan}

Hasil penelitian menjelaskan bahwa pengaruh pemberian pendidikan kesehatan tentang dhf sebelum dan sesudah menunjukkan adanya perubahan dari 58 siswa, yang memiliki pengetahuan pencegahan dhf yang menurun sebelum diberikan pendidikan kesehatan tentang dhf sebanyak 34 siswa $(58,6 \%)$ yang mempunyai pengetahuan pencegahan dhf yang cukup namun setelah diberikan pendidikan kesehatan tentang dhf hasilnya pengetahuan pencegahan dhf yang kurang $39(67,2 \%)$ dan yang mempunyai pengetahuan pencegahan dhf yang cukup 12 $(20,7 \%)$. Hal ini sesuai dengan uji analisis non parametrik dari uji Wilcoxon didapatkan hasil sesudah $<$ sebelum dilakukan pendidikan kesehatan hal ini ditunjukkan dengan tidak adanya pengetahuan pencegahan dhf setelah diberikan pendidikan kesehatan, yaitu dengan nilai Asymp (2 tailed) $\alpha=0,000$ yang berarti $p$ value $0,000<0,05$ dengan demikian $\mathrm{H} 1$ diterima yang berarti ada pengaruh pendidikan kesehatan tentang $D H F$ terhadap pengetahuan pencegahan dhf di PONDOK PUTRI Wilayah MILAQ AL-QODIRI Jember.

\section{KESIMPULAN DAN SARAN}

\subsection{KESIMPULAN}

Berdasarkan hasil penelitian maka peneliti menyimpulkan bahwa pengetahuan pencegahan dhf di SANTRI PONDOK PUTRI Al-Qodiri Jember sebagai berikut :

7.1.1 Bahwa dari 34 santri pondok putri yang pengetahuan pencegahan dhf sebagian besar memiliki pengetahuan pencegahan dhf

7.1.2 Sebagian besar peran santri pondok putri di wilayah MILAQ AL-QODIRI Jember mempunyai peran tinggi

7.1.3 Ada pengaruh pendidikan kesehatan tentang dhf terhadap pengetahuan pencegahan dhf pada santri pondok putri wilayah MILAQ AL-QODIRI Jember di dapatkan nilai signifikan p-value : nilai $\alpha<0,05$ dengan demikian H1 diterima 


\subsection{SARAN}

7.1.1 Bagi instansi terkait dalam hal ini Pondok untuk lebih sering melakukan promosi kesehatan di pondok-pondok agar pengetahuan pencegahan dhf di pondok dapat optimal khususnya tentang masalahmasalah kesehatan untuk menjaga kebersihan merupakan program pondok untuk santri putri.

7.1.2 Bagi responden untuk membantu pengetahuan pencegahan dhf tentang masalah-masalah tentang kesehatan pada santri putri hendaklah sesering mungkin membaca buku tentang kesehatan dan juga bisa memperoleh informasi dari media internet.

7.1.3 Bagi instansi pendidikan hendaknya melakukan suatu kegiatan rutin pemeriksaan kesehatan di lingkungan pondok agar

pondok mengetahui masalah-masalah kesehatan santri pondok.

\subsubsection{Untuk peneliti selanjutnya} diharapkan dapat melakukan penelitian lain yang berhubungan dengan pendidikan kesehatan atau pengetahuan pencegahan dhf.

\section{DAFTAR PUSTAKA}

Ahmad Kholid, Promosi Kesehatan

Semarang, April 2012

Azrul Azwar, Modul Promosi Kesehatan di

Masyarakat, https

://www.google.co.id/search?

$\mathrm{q}=$ alamat+http+daftar+pustaka+menurut $+\mathrm{w}$

ood\%2C1992+dalam+azwar+1983\&btn

$\mathrm{G}=\& \mathrm{ie}=\mathrm{UTF}-8$

Budioro (1998).Pengantar Pendidikan

Kesehatan Masyarakat Semarang.FKM

UNDIP

Djunaedi, 2006, Demam Berdarah Dengue, Malang Universitas Muhammadiyah

Depkes, RI.,(1998). Pencegahan dan Pemberantasan Demam Berdarah Dengue Di Indonesia , Jakarta, Depkes R.I., Ditje.PP\&PL

Darmowondawo.2001.Demam Berdarah

Dengue

Depkes RI.2005.Pencegahan dan Pemberantasan Demam Berdarah Dengue Di Indonesia.Jakarta : Dirjen PP \& PL

Herawani, (2001). Promosi Kesehatan

.Jakarta : PT Rineka Cipta 
Hadinegoro et al.(2001) Tatalaksana Demam

Berdarah Dengue Di Indonesia Jakarta :Depkes RI

Ihsan Jaya 2008 Hubungan Kadar

Hematokrit Dengan Derajat Klinis DBD $\underline{\text { https }}$

://www.google.co.id/search?q=jurnal+patog enesis+dhf\&btn $\mathrm{G}=\& \mathrm{ie}=\mathrm{UTF}-8$ Akses 0103-2016 Pukul 17.40 WIB

Kemenkes RI, 2011. Profil Kesehatan

Indonesia.Jakarta : Kemenkes RI

Kandun, 2000. Manual Pemberantasan

Penyakit Menular Jakarta : Informedika

Nursalam. (2013).Konsep Penerapan

Metode Penelitian .Konsep Penerapan

Metode Penelitian Ilmu Keperawatan.

Jakarta : Salemba Medika.

Notoadmojo, S. (2012). Metodologi

penelitian kesehatan Jakarta : Rineke Cipta.
Notoatmodjo.S.2003 Ilmu Kesehatan Masyarakat Prinsip- prinsip Dasar Jakarta : Rineka Cipta

Nursalam, 2011 Manajemen Keperawatan : Aplikasi dalam Praktik keperawatan Profesional Edisi3. Jakarta : Salemba Medika

Prof. Dr. Sugiyono, Metode Penelitian Pendidikan Pendekatan Kuantitatif , Kualitatif, dan $R \& D$

Rohmad Adi Candra 2014 Asuhan Kep. Pada Saudara F Dengan DHF Dibangsal

Ultazam Rs. Pku

https://www.google.co.id/search?q=jurnal+p enatalaksanaan + medis $+\mathrm{dhf}+\& b$ tn $\mathrm{G}=$ \&ie=UTF-8 Akses 06-03-2016 Pukul 12.55WIB

Soekidjo, (2003),Ilmu Kesehatan Masyarakat, Jakarta: Rineka Cipta

Peneliti

Eka Suryaningtyas, S.Kep., M.Kes

NIDN: 0731018602 